\title{
The 6-min walk distance in healthy subjects: reference standards from seven countries
}

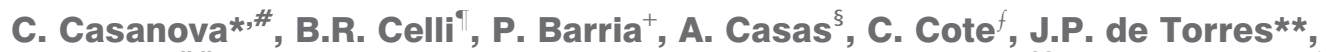 \\ J. Jardim ${ }^{\# \#}$, M.V. Lopez ${ }^{\top \uparrow}$, J.M. Marin ${ }^{++}$, M. Montes de Oca ${ }^{\S \S}$, V. Pinto-Plata ${ }^{f f}$ \\ and A. Aguirre-Jaime ${ }^{\#}$ on behalf of the Six Minute Walk Distance Project (ALAT)***
}

ABSTRACT: The 6-min walk distance (6MWD) predicted values have been derived from small cohorts mostly from single countries. The aim of the present study was to investigate differences between countries and identify new reference values to improve 6MWD interpretation.

We studied 444 subjects (238 males) from seven countries (10 centres) ranging $40-80$ yrs of age. We measured 6MWD, height, weight, spirometry, heart rate (HR), maximum HR (HRmax) during the 6-min walk test/the predicted maximum HR (HRmax \% pred), Borg dyspnoea score and oxygen saturation.

The mean \pm SD 6 MWD was $571 \pm 90 \mathrm{~m}$ (range 380-782 m). Males walked $30 \mathrm{~m}$ more than females $(p<0.001)$. A multiple regression model for the 6MWD included age, sex, height, weight and HRmax \% pred (adjusted $r^{2}=0.38 ; p<0.001$ ), but there was variability across centres (adjusted $\left.r^{2}=0.09-0.73\right)$ and its routine use is not recommended. Age had a great impact in 6MWD independent of the centres, declining significantly in the older population $(\mathbf{p}<\mathbf{0 . 0 0 1})$. Age-specific reference standards of 6MWD were constructed for male and female adults.

In healthy subjects, there were geographic variations in 6MWD and caution must be taken when using existing predictive equations. The present study provides new 6MWD standard curves that could be useful in the care of adult patients with chronic diseases.

KEYWORDS: Geographic variability, healthy subjects, reference values, 6-min walk test

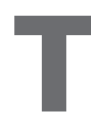
he 6-min walk test (6MWT) has gained importance in the assessment of functional exercise capacity in patients with chronic respiratory disease. It has proved to be reliable, inexpensive, safe and easy to apply [1-3]. In addition, it correlates well with important outcomes including death [4-8].

Important differences in the distance walked have been observed in some studies performed in healthy subjects $[9,10]$. It is possible that differences in methodology and study populations could influence the results. Furthermore, most of the published predictive equations show a high variability in their predictive power, suggesting that others factors usually not considered in the performance of the test could play an important role in the distance walked $[9,11-14]$.

The 6MWT guidelines were reported by the American Thoracic Society (ATS) 7 yrs ago, at a time when reference equations from healthy population-based samples were not available.
The guidelines encouraged investigators to publish reference equations using these new guidelines [1]. However, the series published until now have included a small number of individuals from a single region [9-13]. Currently, there are no universally accepted reference equations for clinical use and there are no available data from multicentre studies evaluating the possible regional differences of this test. We therefore conducted a cross-sectional multicentre study in normal volunteers, with age ranging $40-80$ yrs, following the standardised approach provided by the American Thoracic Society (ATS) guidelines.

\section{METHODS}

\section{Subjects}

We prospectively studied 444 subjects (238 males) from 10 cities in seven countries (São Paulo in Brazil; Santiago in Chile; Bogota in Colombia; Pamplona, Santa Cruz de Tenerife and Zaragoza in Spain; Montevideo in Uruguay; Boston, MA and Tampa, FL in the USA; and
AFFILIATIONS

*Pulmonary Dept, and

${ }^{\text {\#} R e s e a r c h ~ U n i t, ~ H o s p i t a l ~}$

Universitario La Candelaria, Tenerife,

**Clínica Universitaria de Navarra,

Pamplona,

${ }^{++}$Hospital Miguel Servet, Zaragoza, Spain.

"Pulmonary Division, Brigham and Women's Hospital,

${ }^{f f}$ Caritas, St Elizabeth's Medical Center, Boston, MA,

${ }^{f}$ Respiratory Division, Bay Pines VA Medical Center, St Petersburg, FL, USA.

+Universidad Católica de Chile,

Santiago, Chile.

${ }^{\S}$ Fundación Neumológica

Colombiana, Bogota, Colombia.

\#\# Universidad Estadal do Brasil, São

Paulo, Brazil.

"Universidad de Uruguay,

Montevideo, Uruguay.

§§ Universidad Central de Venezuela,

Caracas, Venezuela.

${ }^{* * *}$ A full list of the other members of the Six Minute Walk Distance Project

can be found in the

Acknowledgements section.

CORRESPONDENCE

C. Casanova

Respiratory Research Unit,

Pulmonary Dept, Universidad de La Laguna

Hospital Universitario La Candelaria

Carretera del Rosario no. 145

38010 Santa Cruz de Tenerife

Spain

E-mail: ccasanova@canarias.org

Received:

Dec 102009

Accepted after revision:

April 302010

First published online:

June 042010

Online ISSN 1399-3003 
Caracas in Venezuela) in November 2005-May 2008. We attempted to balance the recruitment of subjects by sex, decades of age and centre. Most of the subjects were hospital workers and relatives of patients. They were included if they met the following criteria: 1) age $40-80$ yrs; 2) no history of chronic disease that could influence their exercise capacity; 3 ) active but not involved in any competitive sport. For the analysis of the relationship between heart rate (HR) and 6-min walk distance (6MWD), we excluded any subject on medications that could affect HR, such as $\beta$-blockers or calcium channel blockers. All subjects gave informed consent to participate in the study and ethical committees from each site approved the study protocol.

\section{Procedure}

Smoking history and blood pressure were recorded. Weight and height were measured and used to calculate body mass index. Lung function was assessed by spirometry according to ATS/European Respiratory Society (ERS) guidelines [15]. The presence and degree of comorbidity was estimated using the Charlson index [16]. We registered the medication taken by the patients. Subjects were questioned about involvement in regular, self-reported physical activity in the previous three months. The subjects were classified as "active" (self reported physical activity: lower extremities exercise for $\geqslant 30 \mathrm{~min}$, three or more times per week) or "sedentary" [17].

\section{MWT}

Two 6MWTs were performed following ATS guidelines [2]. The evaluated parameters were 6MWD in $\mathrm{m}$ and changes in oxygen saturation $\left(\mathrm{Sp}, \mathrm{O}_{2}\right)$ during exercise measured using a lightweight portable pulse oximeter. The longest 6MWD of two tests (performed the same day and separated by $\geqslant 20 \mathrm{~min}$ ) was the primary outcome measure. To determine the effort made by the participants, we also registered HR during the test and determined the maximal HR (HRmax). The predicted HRmax (HRmax \% pred) was derived from the formula HRmax $=220-$ age.

Pre- and post-6MWT dyspnoea were measured using the Borg scale [18]. Although all subjects performed the 6MWT according to the standard ATS guidelines, we determined the effort level using the ratio between HRmax during the test and HRmax $\%$ pred (HRmax/HRmax \% pred).

\section{Statistical analyses}

Data are presented as mean \pm SD for normally distributed variables or median (5th-95th percentile) for those with nonnormal distribution. Variables comparisons were performed using t-tests or ANOVA with Bonferroni post hoc tests, MannWhitney U-tests or Kruskal-Wallis H-tests and Pearson Chisquared tests according to their type, distribution and number of the group involved in the comparisons. Correlations were estimated by Pearson's or Spearman coefficients according to type and distribution of variables. A forward stepwise multiple linear regression model was used to evaluate the predictive value of the different factors to explain the 6MWD. Centile charts were constructed using the 10th, 25th, 50th and 75th percentiles of the best 6MWD at 10-yr intervals for the male and female subjects. Significance levels for all tests were established as a two-tailed p-values $\leqslant 0.05$. Calculations were performed using SPSS 15.0 (SPSS Inc., Chicago, IL, USA).

\section{RESULTS}

\section{Subject characteristics}

The cohort of 444 subjects was distributed as follows: 133 from Spain (40 from Tenerife, 66 from Zaragoza and 27 from Pamplona), 192 from South America (40 from Uruguay, 26 from Venezuela, 39 from Colombia, 47 from Brazil and 40 from Chile) and 119 from USA (62 from Boston and 57 from Tampa). The anthropomorphic and clinical characteristics are shown in table 1 . Most subjects were nonobese $(81 \%)$, nonsmokers $(69 \%)$ who frequently reported being active $(71 \%)$ and had very few comorbidities.

\section{MWT}

Overall group

None of the tests performed required interruption and none of the individuals required assistance during the 6MWT. The mean \pm SD $6 \mathrm{MWD}$ was $571 \pm 90 \mathrm{~m}$ (range $380-782 \mathrm{~m}$ ). On average, the subjects walked $12 \mathrm{~m}$ more in the second test compared with the first $(p<0.001)$. The second walk was longer in $69 \%$ of the subjects (table 2 ). This difference was independent of sex (13 m for males and $11 \mathrm{~m}$ for females). The 6MWD was $30 \mathrm{~m}$ greater in males than in females $(585 \pm 96 \mathrm{~m}$ versus $555 \pm 81 \mathrm{~m} ; \mathrm{p}<0.001)$. The older subjects walked shorter distances than the younger subjects (4049 yrs of age, $611 \pm 85 \mathrm{~m}$; 50-59 yrs of age, $588 \pm 91 \mathrm{~m}, 60$ $69 \mathrm{yrs}$ of age, $559 \pm 80 \mathrm{~m} ; 70-80 \mathrm{yrs}$ of age, $514 \pm 71 \mathrm{~m}$; $p<0.001)$. The effect of age on the 6MWD became significant at $\geqslant 60$ yrs of age and this happened independent of sex (fig. 1).

The level of self-reported physical activity of the subjects did not influence 6MWD ("active" $573 \pm 92 \mathrm{~m}$ versus "sedentary" $568 \pm 88 \mathrm{~m} ; \mathrm{p}=0.581)$. Also, the presence of comorbidities (Charlson score $\geqslant 1$ ) did not affect the walked distance $(567 \pm 85 \mathrm{~m}$ verus $563 \pm 87 \mathrm{~m} ; \mathrm{p}=0.719)$. Although the mean $\mathrm{Sp}, \mathrm{O}_{2}$ decreased during the test $(0.7 \% ; \mathrm{p}<0.001)$, it was clinically irrelevant. Almost $50 \%$ of subjects increased their dyspnoea score by $\geqslant 1$ unit (table 2 ).

\begin{tabular}{|c|c|c|}
\hline TABLE 1 & \multicolumn{2}{|c|}{$\begin{array}{l}\text { Anthropometric and clinical characteristics of the } \\
\text { subjects }\end{array}$} \\
\hline \multicolumn{2}{|l|}{ Subjects n } & 444 \\
\hline \multicolumn{2}{|c|}{ Males/females $n$} & 238/206 \\
\hline \multicolumn{2}{|c|}{ Non-white subjects } & $23(5)$ \\
\hline \multicolumn{2}{|l|}{ Age yrs } & $58(42-76)$ \\
\hline \multicolumn{2}{|l|}{$40-49$} & $109(24)$ \\
\hline \multicolumn{2}{|l|}{$50-59$} & $129(29)$ \\
\hline \multicolumn{2}{|l|}{$60-69$} & $118(27)$ \\
\hline \multicolumn{2}{|l|}{$70-80$} & $88(20)$ \\
\hline \multicolumn{2}{|l|}{$\mathrm{BMI} \mathbf{k g} \cdot \mathrm{m}^{-2}$} & $27 \pm 4$ \\
\hline \multicolumn{2}{|c|}{ Smoking history pack-yrs } & $20(5-52)$ \\
\hline \multicolumn{2}{|c|}{ Active smoker \% } & 3 \\
\hline \multicolumn{2}{|c|}{ Nonsmoker \% } & 69 \\
\hline \multicolumn{2}{|c|}{ Sedentary activity \% } & 29 \\
\hline \multicolumn{2}{|c|}{ Charlson score $\geqslant 1$} & 12 \\
\hline
\end{tabular}




\begin{tabular}{|c|c|c|}
\hline TABLE 2 & \multicolumn{2}{|c|}{$\begin{array}{l}\text { Cardiopulmonary parameters at rest and during } \\
\text { the } 6 \text {-min walk test (6MWT) }\end{array}$} \\
\hline \multicolumn{2}{|l|}{ Subjects $n$} & 444 \\
\hline \multicolumn{2}{|l|}{ FEV 1 L } & $2.78 \pm 0.74$ \\
\hline \multicolumn{2}{|l|}{$\mathrm{FEV}_{1} \%$ pred } & $100 \pm 14$ \\
\hline \multicolumn{2}{|l|}{ FVC \% pred } & $102 \pm 14$ \\
\hline \multicolumn{2}{|c|}{$\mathrm{Sp}, \mathrm{O}_{2} \%$ pred at rest } & $96.5 \pm 1.7$ \\
\hline \multicolumn{2}{|c|}{${\mathrm{Sp}, \mathrm{O}_{2}}_{\mathrm{O}} \%$ pred post-6MWT } & $95.8 \pm 2.4^{\#}$ \\
\hline \multicolumn{2}{|c|}{ Respiratory rate at rest breaths $\min ^{-1}$} & $16 \pm 2$ \\
\hline \multicolumn{2}{|c|}{$\mathrm{HR}$ at rest beats $\cdot \mathrm{min}^{-1}$} & $76 \pm 10$ \\
\hline \multicolumn{2}{|c|}{ HRmax/HRmax \% pred } & $73 \pm 13$ \\
\hline \multicolumn{2}{|c|}{ End Borg dyspnoea score } & $0.5(0-3)$ \\
\hline \multicolumn{2}{|c|}{ Borg dyspnoea score after $6 \mathrm{MWT} \geqslant 1$} & 44 \\
\hline \multicolumn{2}{|l|}{ 1st test } & $554 \pm 89$ \\
\hline \multicolumn{2}{|l|}{ 2nd test } & $565 \pm 90^{\circ}$ \\
\hline \multicolumn{2}{|l|}{ Best } & $571 \pm 90$ \\
\hline \multicolumn{3}{|c|}{ 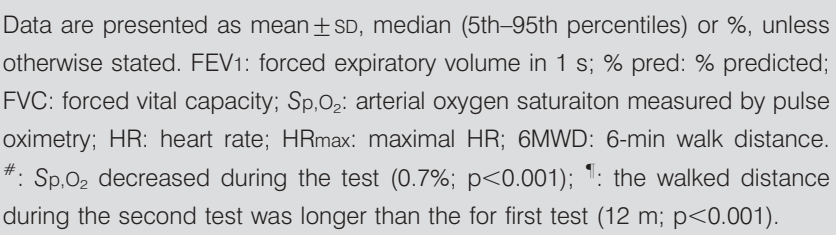 } \\
\hline
\end{tabular}

The mean \pm SD HRmax/HRmax \% pred was $73 \pm 13 \%$ and this variable showed a significant correlation with the $6 \mathrm{MWD}$ $(\mathrm{r}=0.34 ; \mathrm{p}<0.001) .144$ volunteers $(26 \%$ from Spain, $31 \%$ from South America and 43\% from the USA) did not reach the 25th percentile $(\geqslant 65 \%)$ of $\mathrm{HRmax} / \mathrm{HRmax} \%$ pred during the $6 \mathrm{MWT}$. This group had some differences in comparison with the rest of the group (table 2): they were younger (55 yrs (5th95th percentiles $42-70 \mathrm{yrs}$ ) versus $60 \mathrm{yrs}$ (5th-95th percentiles $42-77$ yrs); $\mathrm{p}<0.001$ ), were less likely to be comorbid ( $5 \%$ versus $17 \%, \mathrm{p}=0.001)$ and, most importantly, they walked a significantly shorter distance $(548 \pm 78 \mathrm{~m} ; \mathrm{p}<0.001)$.

Using linear stepwise multiple regression analysis, the best predictive equation for the 6MWD included age, height, weight, sex and HRmax/HRmax \% pred:

Predicited 6MWD $=361-($ age in yrs $\times 4)+($ height in $\mathrm{cm} \times 2)+$ $(\mathrm{HR}$ max $/ \mathrm{HR}$ max \% pred $\times 3)-($ weight in $\mathrm{kg} \times 1.5)-30$ (if females). This model accounted for $38 \%$ of the total variance of the 6MWD. Others variable, including forced expiratory volume in $1 \mathrm{~s}$ and Borg dyspnoea score, did not show a significant independent association with 6MWD.

\section{Variability across centres}

The anthropometric characteristics by centres are shown in table 3. There were not significant differences by age between centres and, with the exception of the Florida population, the distributions of subjects were well balanced by sex. In addition, subjects from USA were taller and heavier. There were substantial differences in distance walked between countries (fig. 2): Brazilian subjects walked $100 \mathrm{~m}$ more than subjects from Venezuela or Chile; in Spain, subjects from Tenerife and Pamplona walked more than those from Zaragoza (table 3). Although the HRmax/HRmax \% pred were higher in the centres
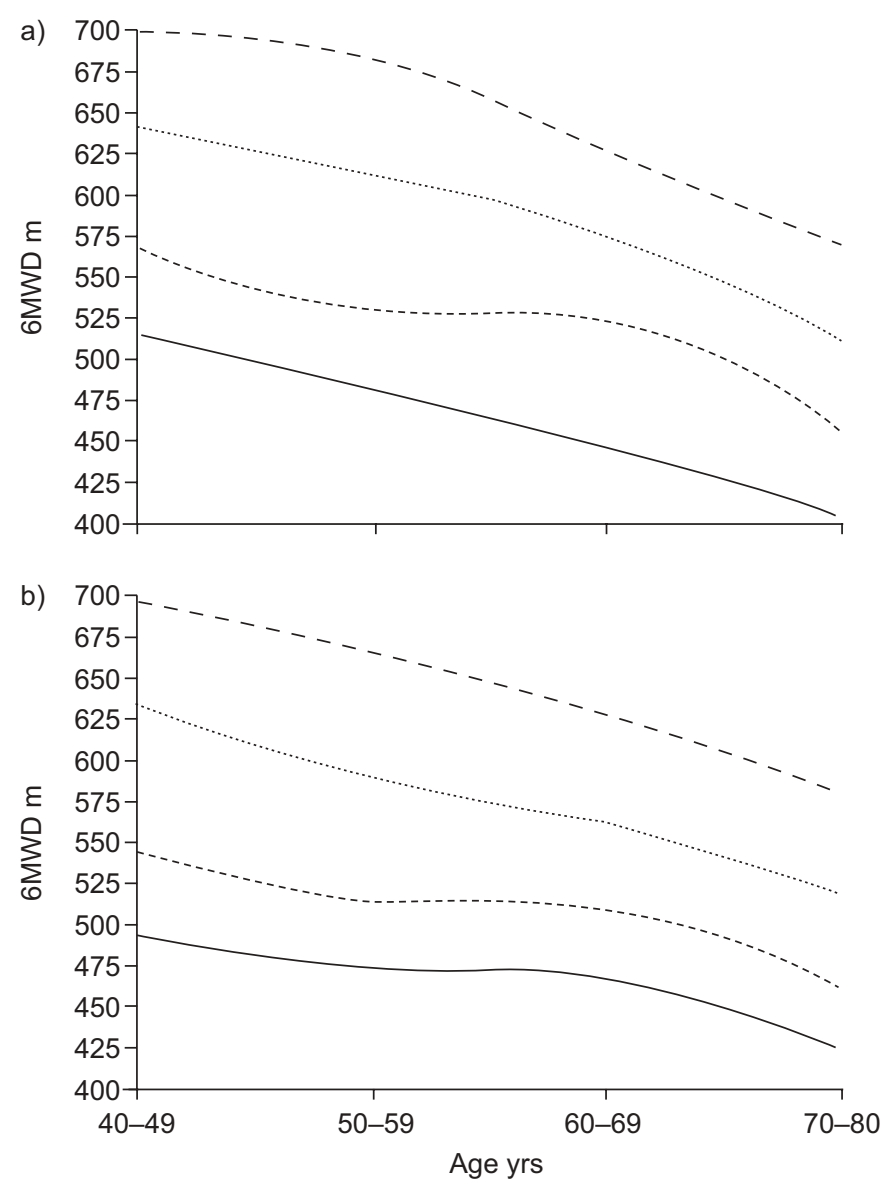

FIGURE 1. Age-based reference curves for 6-min walk distance (6MWD) in normal a) males and b) females divided into 10th $(-)$, 25th (-----), 50th (…......) and 75 th $(---)$ percentiles.

with longer 6MWD $(r=0.908 ; \mathrm{p}<0.0003$; table 3$)$, these differences remained even if the effort was normalised by this factor: that is, progressive increases in achieved heart rate HRmax/ HRmax $\%$ pred $(65 \%, 70 \%$ and $75 \%$ ) were associated with longer distance walked in all centres, but the differences among centres, remained significant $(\mathrm{p}<0.001)$.

The predictive equation had an important variability across the centres (adjusted $r^{2}=0.09-0.73$ ) and explained $<30 \%$ of the $6 \mathrm{MWD}$ variance in four centres. In addition, not all of the variables had a predictive role in each centre. Therefore, we could not obtain an adequate predictive equation for the population as a whole. However, age had a great impact on $6 \mathrm{MWD}$ in most of the centres and we rejected the equation. Therefore, we constructed age-specific normative charts for male and female subjects from original 6MWD data (fig. 1).

The clinical applicability of the curves here proposed is shown in figure 3, where the values reported from studies of different clinical conditions (pulmonary hypertension, congestive heart failure (CHF), interstitial pulmonary fibrosis and chronic obstructive pulmonary disease (COPD)) are plotted in the nomogram we constructed. The values for the 6MWD in those studies was clearly below the normal values in all of the reports and it was lower the more severe the stage in $\mathrm{CHF}$ and COPD [7, 19-21]. 
TABLE 3 Anthropometric characteristic and 6-min walk distance (6MWD) of the subjects by region

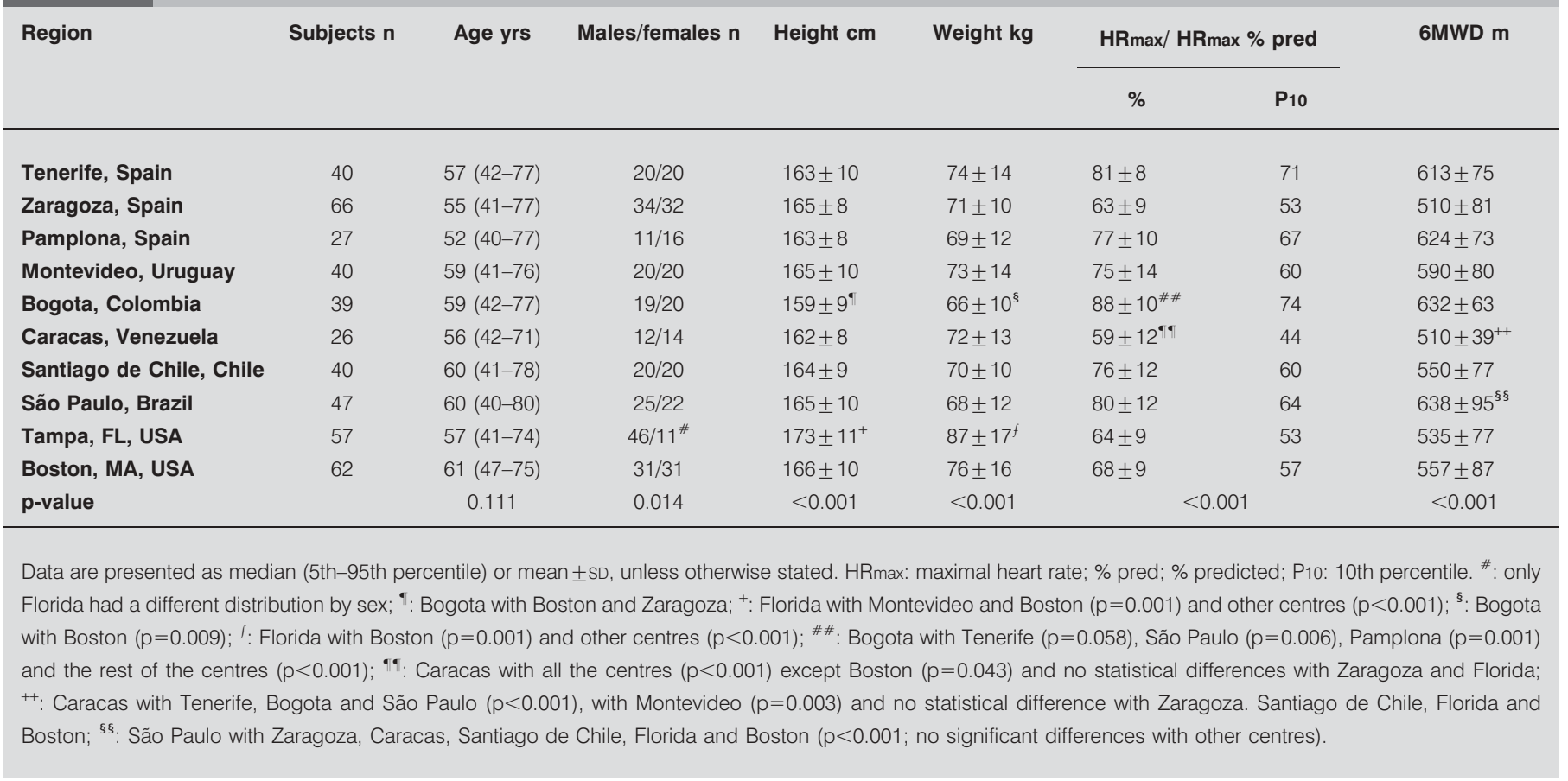

\section{DISCUSSION}

To our knowledge, this is the first international, multicentre study evaluating the geographic variations of 6MWD in a large cohort of healthy adults that performed the 6MWT following the ATS guidelines. There were two important findings. First, there were 6MWD geographic variations that cannot be explained by anthropometric factors even when the effort was adjusted using HRmax/HRmax \% pred. Secondly, the
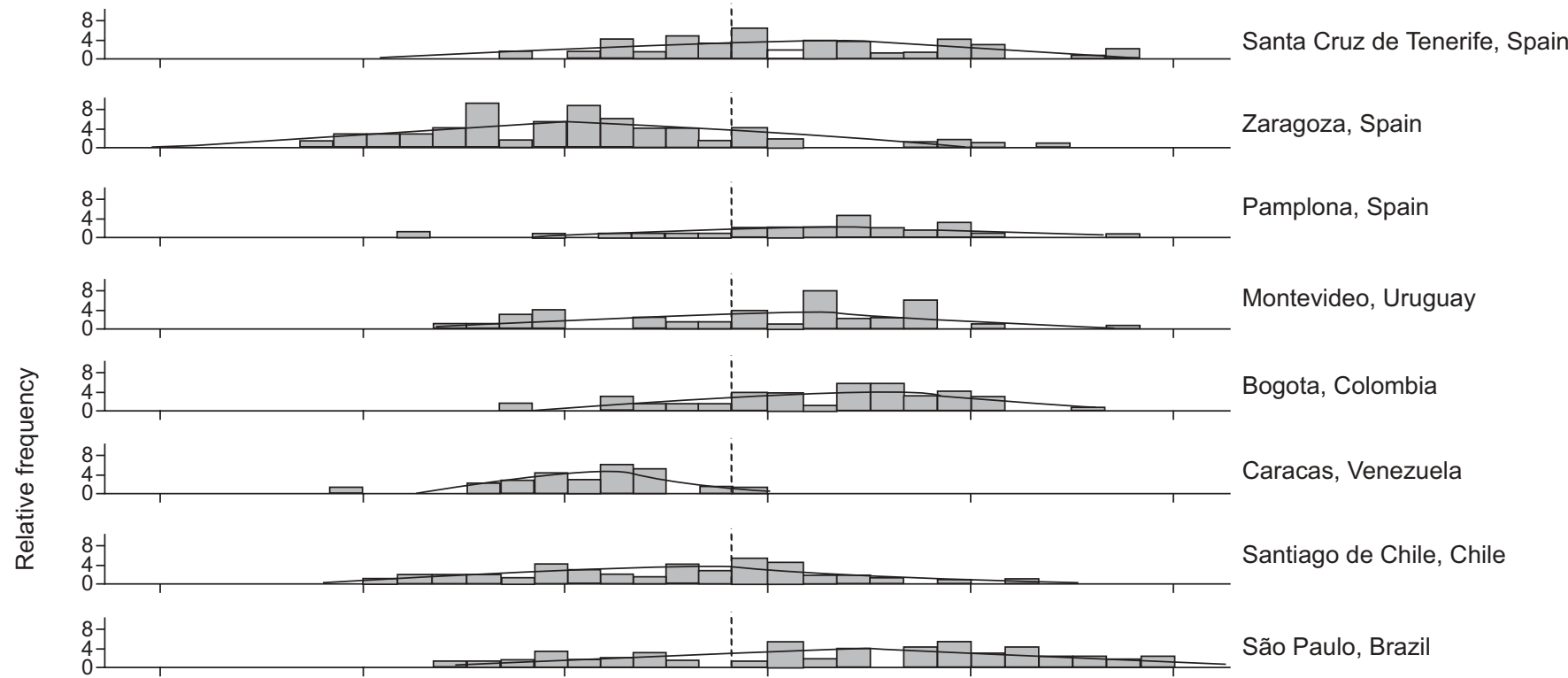

Bogota, Colombia

Caracas, Venezuela

Santiago de Chile, Chile

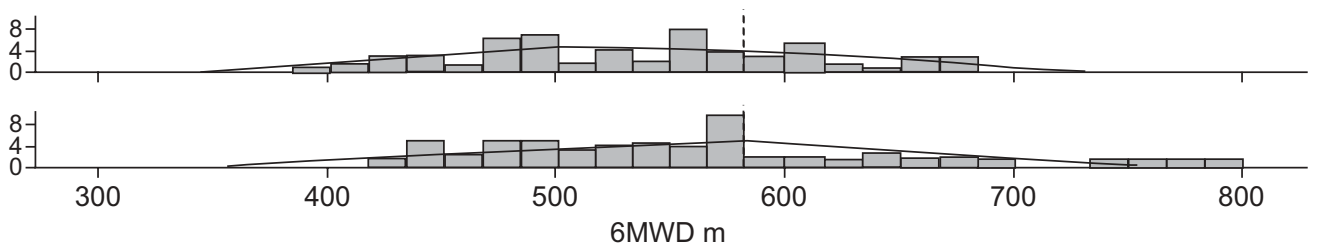

São Paulo, Brazil

Tampa, FL, USA

Boston, MA, USA

FIGURE 2. Histogram of the 6-min walk distance (6MWD) in the different centres. —-: frequency distribution; -----: mean (entire population). 


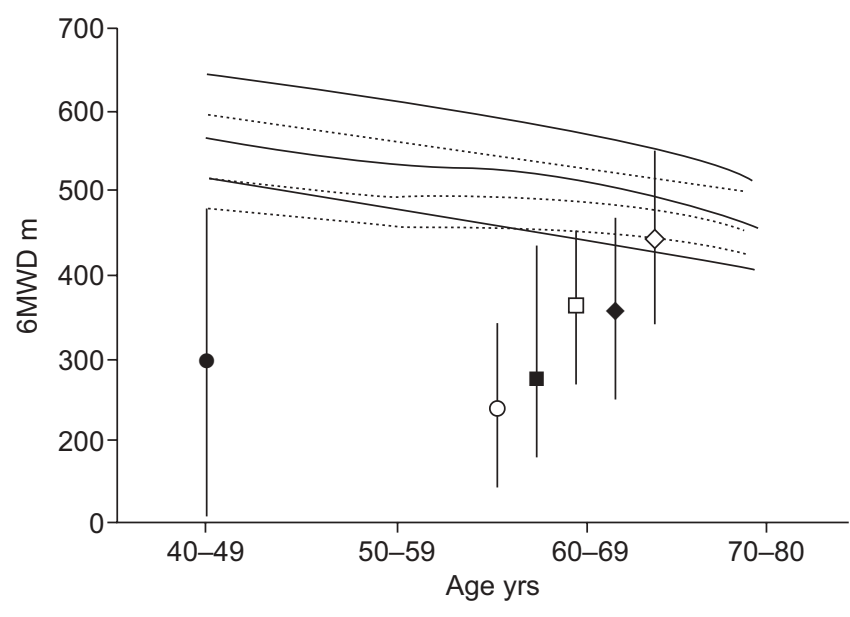

FIGURE 3. Percentiles (10th, 25th and 50th) curves for 6-min walk distance (6MWD; - : males; -----: females) compared with the mean (range) published data of the 6MWD for several important chronic diseases: primary pulmonary

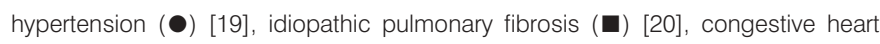
failure subdivided into New York Heart Association (NYHA) stages II ( $\square$ ) and III-IV (O) [21], and chronic obstructive pulmonary disease subdivided into Global Intitative for Obstructive Lung Disease stages II $(\diamond)$ and III-IV $(\diamond)$ [7]

present work confirmed the importance of age and sex in the distance walked and proposes new reference standards curves for the use of 6MWD in clinical practice.

The $6 \mathrm{MWT}$ is used because it provides useful information of functional capacity in patients with cardiorespiratory diseases. In the last decade, six studies have evaluated the 6MWT in healthy adults in order to provide reference values for the 6MWD [3, 9-13]. In two studies, the population profiles were either too young or old [3, 13]. In three other studies [10-12] the distance walked was very similar $(\sim 600 \mathrm{~m})$ and much longer than the values reported in the largest cohort performed to date in the USA [9]. The differences observed in these studies suggested the need to explore the factors responsible for the differences and to further standardise the test.

The first important finding in our study is the presence of differences between centres even following the same standardised 6MWD test. Differences across centres were large and could influence the results of studies conducted in different regions of the world. The possible reasons for these important variations are unlikely to be due to anthropometric factors, because similar values were found across sites. If anything, subjects in the USA, where the values for walked distance was lower, were taller than those from the other regions. It is possible that the variability in $6 \mathrm{MWD}$ may be explained by inclusion of other factors, such as speed of habitual walking or cultural aspects related to lifestyle, mood, attitude and motivation of the subject and/or technician.

It could be argued that the intensity of the effort during the test played an important role in the differences found between centres. In fact, this argument could have been valid for some of the published results. Indeed, the age-predicted HRmax were $>75 \%$ in the studies with longer 6MWD [10, 11], whereas it was $<65 \%$ in the cohort studied by ENRIGHT and SHERRILL [9], who reported the shortest walking distance. We believe that our results indicate that the effort needs to be further standardised so that findings can be compared across studies. Indeed, in our cohort, analysis of the results from the patients in the lowest 25th percentile, showed that the increase in HR during the 6MWD was close to that reported by ENRIGHT and SHERRILL [9], supporting the concept that lack of adequate effort may have influenced their results. However, lack of adequate effort can only partially explain our results, because the differences by centres persisted in spite of controlling effort by monitoring HR. Our findings are in agreement with those reported in children, where the difference in HR before and after walk was an important clinical variable associated with the 6MWD [22]. New studies in this area exploring the physiological variables and their response to this form of exercise are necessary [23, 24].

Our study also allowed us to evaluate the learning effect when two standardised tests are performed according to ATS guidelines [25]. The results showed that the second test was, on average, $2 \%$ better than first test, although $27 \%$ of the subjects walked farther in the first test. The difference between the first and second walk that we observed was lower than those previously reported of $3-8 \%$ [10-12] and suggests a consistent methodology across centres.

The most important factor influencing the 6MWD in healthy subjects was age, a variable that has been observed in all previous studies with the exception of the one by CAMARRI et al. [12]. This is possibly related to the smaller sample size (70 subjects) and narrower age range (55-75 yrs) of that study. The effect of age is more evident in patients $>60 \mathrm{yrs}$ of age, independent of sex. GiBBONS et al. [11] had previously suggested that only older females had lower 6MWD. However, in that study, there was a small number of subjects, which could explain the difference with our results. Also, our findings confirm previous studies that showed that the 6MWD is greater in males than females [3, 9-13], a fact also described in patients with COPD [26].

In addition to age and sex, we explored other possible factors that could influence the results of the $6 \mathrm{MWD}$, such as the postwalk Borg dyspnoea score, the self-reported physical activity and the Charlson comorbidity index. Although assessing the post-walk Borg dyspnoea score has been recommended by the ATS guidelines [2], only one study has reported its value after the test. They did not observe any influence of dyspnoea on the $6 \mathrm{MWD}$, and this finding is supported by our results [13]. The lack of effect of the self-reported physical activity on the $6 \mathrm{MWD}$ is consistent with other studies that also failed to demonstrate this association [10-12]. However, it is possible that development of more sensitive physical activity scales could highlight some differences not detected with the instrument used in the current study. Overall, our subjects had a low comorbidity index, a fact that could explain the little influence of this variable on the 6MWD. This contrasts to the findings reported in patients with COPD where comorbidities have an important influence on the 6MWD [27].

About $60 \%$ of the variance in $6 \mathrm{MWD}$ remains unexplained by our model. This finding is consistent with most of the previous studies [3, 9, 11-13], except with that of TROOSTERs et al. [10] who observed that age, height, weight and sex explained $66 \%$ of the variance in $6 \mathrm{MWD}$ in a small Belgian population. 
In a novel approach, we provide reference percentile curves that could be useful in clinical practice. As can be seen in figure 3, the reported absolute values from patients with different conditions known to affect functional capacity are below the lower confidence interval of the calculated nomograms [7, 19-21], providing validity to the applicability of these curves. Although theoretically, an accurate predictive equation of reference value for comparison would be desirable, none of the equations has been sufficiently precise to provide such information. Furthermore, the absolute distance walked is a better predictor of mortality than that obtained from the application of corrective equations [8]. In addition, the response of the distance walked to intervention is also best reported as an absolute value in $\mathrm{m}[28,29]$ without corrections by predictive equations. The age-specific nomograms for males and females proposed here can simplify the interpretation of individual results in clinical practice and trials and can provide graphic evidence of changes in values over time or after interventions.

The present study has some limitations. First, the samples of subjects in two cities (Caracas and Pamplona) were small, but differences were observed across other centres. Secondly, the participants were a not a random sample from the population of adults in each city. However, the subjects represented all age groups and were balanced by sex. Thirdly, the reference curves can not be used in subjects $<40$ yrs of age because they were not included. However, the $40-80$-yr range is the age where most of the patients with cardiopulmonary pathologies express their clinical disease. Finally, other potential variables not included in the present study could improve the variance explained by our predictive equations. Among them, psychological factors, such as depression and anxiety, which have demonstrated some influence on exercise performance [14]. Nevertheless, in our population, only seven (2\%) subjects reported depression and 12 individuals were taking related medications, a value that is much lower than the prevalence reported in studies including patients with chronic cardiorespiratory diseases. However, if we had included more variables, the model would be less simple and efficient, and more difficult to implement in clinical practice. As it stands, this study included all the factors that have shown a strong and independent association with the 6MWD.

In summary, for the first time, we report in a healthy population of both sexs the existence of geographic differences in 6MWD that is independent of the standardisation technique. We propose new standard reference curves based on factors proven to have a significant impact on the 6MWD independent of the region of the world. These new 6MWD standards curves could be useful for the care of adult patients but further studies involving subjects from others populations and races will be needed for comparison.

\section{STATEMENT OF INTEREST}

None declared.

\section{ACKNOWLEGEMENTS}

The other members of the Six Minute Walk Distance Project (ALAT) are as follows: A. Abraham (Caritas-St. Elizabeth's Medical Center, Boston, MA, USA), P. Aguiar (Fundación Neumológica Colombiana, Bogota, Colombia), S. Carrizo (Hospital Miguel Servet, Zaragoza,
Spain), L. Dordelly (Bay Pines VA Medical Center, St Petersburg, FL, USA), M.M. Lakuntza (Clínica Universitaria de Navarra, Pamplona, Spain), C. Lisboa (Universidad Católica de Chile, Chile, Santiago), M. Mamchur (Universidad de Uruguay, Montevideo, Uruguay), M. Sifonte (Universidad Central de Venezuela, Caracas, Venezuela) and A.T. Tuffanin (Universidad Estadal do Brazil, São Paulo, Brazil).

\section{REFERENCES}

1 Sciurba FC, Slivka WA. Six-minute walk-testing. Semin Resp Crit Care Med 1998; 9: 383-391.

2 ATS Statement: Guidelines for the six-minute walk test. Am J Respir Crit Care Med 2002; 166: 111-117.

3 Enright PL, McBurnie MA, Bittner V, et al. The 6-min walk test. A quick measure of functional status in elderly adults. Chest 2003; 123: 387-398.

4 Casanova C, Cote C, de Torres JP, et al. The inspiratory lung capacity ratio predicts mortality in patients with COPD. Am J Respir Crit Care Med 2005; 171: 591-597.

5 Pitta F, Troosters T, Spruit MA, et al. Characteristics of physical activities in daily life in COPD. Am J Respir Crit Care Med 2005; 171: 972-977.

6 Pinto-Plata VM, Cote C, Cabral H, et al. The 6-min walk distance: change over time and value as a predictor of survival in severe COPD. Eur Respir J 2004; 23: 28-33.

7 Casanova C, Cote C, Marín JM, et al. Distance and oxygen desaturation during six minute walk test as predictors of longterm mortality in patients with COPD. Chest 2008; 134: 746-752.

8 Cote CG, Casanova C, Marín JM, et al. Validation and comparison of reference equations for the six-minute walk test. Eur Respir J 2008; 31: 571-578.

9 Enright PL, Sherril DL. Reference equations for the six-minute walk in healthy adults. Am J Respir Crit Care Med 1998; 158: 1384-1387.

10 Troosters T, Gosselink R, Decramer M. Six minute walking distance in healthy elderly subjects. Eur Respir J 1999; 14: 270-274.

11 Gibbons WJ, Fruchter N, Sloan S, et al. Reference values for a multiple repetition 6-minute walk test in healthy adults older than 20 years. J Cardiopulm Rehabil 2001; 21: 87-93.

12 Camarri B, Eastwood PR, Cecins NM, et al. Six minute walk test distance in healthy subjects aged 55-75 years. Respir Med 2006; 100: 658-665.

13 Chetta A, Zanini A, Pisi G, et al. Reference values for the 6-min walk test in healthy subjects 20-50 years old. Respir Med 2006; 100: 1573-178

14 Lord SR, Menz HB, Pod B. Physiologic, psychologic, and health predictors of 6-minute walk performance in older people. Arch Phys Med Rehabil 2002; 83: 907-911.

15 Lung function testing; selection of reference values and interpretative strategies. American Thoracic Society. Am Rev Resp Dis 1991; 144: 1202-1218.

16 Charlson M, Szatrowsky T, Peterson J, et al. Validation of a combined comorbidity index. J Clin Epidemiol 1994; 47: 1245-1251.

17 American College of Sports Medicine position stand. The recommended quantity and quality of exercise for developing and maintaining cardiorespiratory and muscular fitness in healthy adults. Med Sci Sports Exerc 1990; 22: 265-274.

18 Borg GAV. Psycho-physical bases of perceived exertion. Med Sci Sports Exerc 1982; 14: 377-381.

19 Miyamoto S, Nagaya N, Satoh T, et al. Clinical correlates and prognostic significance of six-minute walk test in patients with primary pulmonary hypertension. Am J Respir Crit Care Med 2000; 161: 487-492.

20 Flaherty KR, Andrei AC, Murray S, et al. Idiopathic pulmonary fibrosis. Prognostic value of changes in physiology and six-minute walk test. Am J Respir Crit Care Med 2006; 174: 803-809. 
21 Rostagno C, Olivo G, Comeglio M, et al. Prognostic value of 6minute walk corridor test in patients with mild to moderate heart failure: comparison with other methods of functional evaluation. Eur J Heart Fail 2003; 5: 247-252.

$22 \mathrm{Li} \mathrm{AM}$, Yin J, Au JT, et al. Standard reference for the 6-minute walk test in healthy children aged 7 to 16 years. Am J Respir Crit Care Med 2007; 176: 174-180.

23 Cahalin L, Pappagianopoulos P, Prevost S, et al. The relationship of the 6-min walk test to maximal oxygen consumption in transplant candidates with end-stage lung disease. Chest 1995; 108: 452-459.

24 Casas A, Vilaro J, Rabinovich R, et al. Encouraged 6-min walking test indicates maximum sustainable exercise in COPD patients. Chest 2005; 128: 55-61.
25 Wu G, Sanderson B, Bittner V, et al. The 6-minute walk test: how important is the learning effect? Am Heart J 2003; 146: 129-133.

26 De Torres JP, Casanova C, Hernández MC, et al. Gender and chronic obstructive pulmonary disease in patients attending a pulmonary clinic. Chest 2005; 128: 2012-2016.

27 Casanova C, Cote CG, Marín JM, et al. The six-minute walk distance: long-term follow up in patients with COPD. Eur Respir J 2007; 29: 535-540.

28 Redelmeier DA, Bayoumi AM, Goldstein RS, et al. Interpreting small differences in functional status: the six minute walk test in chronic lung disease patients. Am J Respir Crit Care Med 1997; 155: 1278-1282.

29 Puhan MA, Mador MJ, Held U, et al. Interpretation of treatment changes in the 6-minute walk distance in patients with COPD. Eur Respir J 2008; 32: 637-643. 